for oxygen has been found, which means that the oxygen solubility values in a number of recent publications are incorrect.

\section{Zoology in South-west Africa}

Cimbebasia, issued by the State Museum, Windhoek, South-west Africa, records present zoological research in that country. No. 8, December 1963, is an interesting account by R. F. Lawrence of the Solifugae of South-west Africa, a country that seems to offer a particularly favourable ecology to theso creatures, for no less than 10 per cent of the 800 known species are found there. Although the paper is primarily systematic, the preliminary sections on the biology of these poculiar arachnids is of special value. Cimbebasia (No. 6; November 1963) contains four papers on various reptiles and one each on mites and diatoms, mostly by members of the Museum's staff.

\section{Boliland Region of Sierra Leone}

A 'BouI' is the term for a flat treeless grassland that is flooded during the rainy season, and a survey of the bolilands was called for in order to delineate areas suitable for rice cultivation. The work was carried out under the Colonial Development and Welfare Scheme, and the results are described by A. R. Stobbs in The Soils and Geography of the Boliland Region of Sierra Leone (Pp. $45+12$ plates. Freetown, Sierra Leone: Government Bookshop, London; Crown Agents for Overseas Governments and Administrations, 1963. 28s.). The area concerned consists of a strip about 140 miles long and 25 miles wide, with an annual rainfall of up to $130 \mathrm{in}$., mainly in a six-month period. The soils of the undulating upland are derived from sandstones and sandy shales; mudstones and shales, weathering into puddled clay subsoils, underlie most of the bolis, which are poor in mineral nutrients and have not attracted settlement as have the more fertile adjacent soils. The mapping of the soils was based on a geomorphological interpretation of aerial photographs, extended by the identification of soil series, which is a method of great value in a large area with poor communications but with uniform climate and geological pattern; six individual typical riverain and individual bolis were also mapped on a large scale to show the effects of variations in height on the flooding régime and to provide a basis for experimental work. The soils are classified, on the system that has already proved of value in West Africa, into the soil groups: oxysols, groundwater laterites, acid gleisols and alluviosols. Typical profiles are described and analytical results are appended, and comparisons are made for planning future development. There is a preliminary description of the existing plant communities by T. S. Bakshi. The land use in the uplands is based on shifting cultivation with bush fallow; there is a wide range of crops, but it is just subsistence farming and there is room for considerable improvement. In the flood plains, water control would enhance the possibility of swamp rice and dry-season pasture.

\section{Witchcraft and Sorcery in Oceania}

IN his presidential address to the Anthropology Soction of the Australian and New Zealand Association for the Advancement of Science, Prof. M. G. Marwick, of Monash University, examined some aspects of the sociology of witcheraft and sorcery (Australian Journal of Science, 26 , No. $9 ;$ 1964). In Oceania, one of the well-founded propositions of the sociology of sorcery and witchcraft does not seem to apply. Elsewhere, especially in Africa, it has been repeatedly recorded that both bolieved attacks and accusations of witcheraft and sorcory occur only between persons already linked by close social bonds, but in Oceania it is more often reported that the sorcerer, who seems to be commoner than the witch, is believed to direct his destructivo magic outside his own group. A corollary to the generalization supportod by the
African material is that the relationship between alleged witch and sorcerer and bolieved victim is not only close. but also strained; and this fact gives a means of detecting. the tension-points of a social structure by the frequency with which attacks of witchcraft and sorcery are believed to occur between persons standing in various relationships. Prof. Marwick suggests that the person who carries out field-work on the sociology of Oceanian sorcery or witcheraft might bear the following points in mind. First, torms such as sorcery and witcheraft must be clearly defined and the differentiation between destructive magic socially approved and that socially condemned should be maintained; for the difference between them is, for clear reasons, matorial to sociological analysis. Secondly, the well-established principle of comparing the ideal with the real applies in this field of enquiry as much as in any other. Thirdly, beliefs in sorcery and witcheraft invariably have a social setting in a sense that they mediate, though they sometimes complicate, the living together of people in the on-going process we call a society. These considerations mean that, fourthly, the field-workor, in collecting his material, has to direct particular attention to the three central characters, the accuser, the alleged soreerer or witch and the believed victim, and to the social relationships, the rivalries and the alliances betweon them. Finally, the ethnographer should again apply a well-established canon of field-work to his particular topic, that is, when he cannot observe the relationships believed to be involved in a particular instanco of misfortune, and even when he can, he should not rely on only one informant for each case, but should record the interpretations of different persons differently placed in relation to the central characters.

\section{Spiral Structure in the Andromeda Nebula}

THE Great Nebula in Andromeda has played an important part in the development of our knowledge of galaxies. The late Dr. Walter Baade initiated many investigations of the Nebula which are now being completed by his colleagues. The results of an examination of the emission nebulæ in the Nebula have just been published (Baade, W., and Arp, H., Astrophys. J., 139, 1027; 1964). At one time it had been thought that no gaseous emission nebulæ were present in the Andromeda Nebula. Baade doubted this, and accordingly photographed the Nebula with the 100-in. telescope at Mount Wilson, using various specially selected combinations of photographic plates and filters. Photographs taken in different wave-length regions were compared, and in all 688 emission nebulæ were catalogued. These objects at first appeared to outline the spiral structure very well, but later work has shown that their interpretation is not easy. Arp (Astrophys. J., 139, 1045; 1964) has made a detailed discussion of the problem. The distribution of the brightest stars must also be considered. Direct photographs have shown that the best representation of the spiral structure is obtained if it is assumed that the Nobula is tilted at an angle of $16^{\circ}$ to the line of sight. When attempts are made to fit the emission nebulæ to this picture difficulties arise. There does not seem to be any tilt angle which, when allowed for, will give a picture of the emission nebulæ looking like a continuous spiral curvo. A much better fit is obtained if the angle of tilt is $11^{\circ}$ to the line of sight. Dr. Arp suggests that the whole plane of the Nebula is warped, with a tilt of $16^{\circ}$ for the side more distant from us, and for the central regions, and a tilt of $11^{\circ}$ for the near-side regions. On this picture the emission nebulæ form a complete spiral. There is evidence that the warping is caused by the companion elliptical galaxy, $M 32$.

\section{Research Scholarship in Environmental Engineering}

Applications are invited from graduates in ongineering or physics who wish to undertake research on problems associated with the study and production of comfortable 